\title{
Peningkatan Kemampuan Mendeskripsikan Sifat-sifat Magnet dengan Pendekatan Scientific Siswa Kelas V SDN Balowerti I Kota Kediri Tahun Pelajaran 2015 / 2016
}

\author{
Endang Sumariati \\ Dinas Pendidikan Kota Kediri \\ SDN Balowerti I \\ Kecamatan Kota-Kota Kediri
}

\begin{abstract}
Abstrak
Hasil belajar siswa pada pembelajaran mendeskripsikan sifat - sifat magnet menunjukkan bahwa 51 \% siswa mendapatkan nilai dibawah KKM. Dari hasil itulah penulis mengadakan penelitian tindakan kelas. Penelitian ini bertujuan untuk memperbaiki KBM dan meningkatkan hasil belajar siswa dengan menggunakan pendekatan scientific. Sasaran perbaikan pembelajaran ini adalah siswa kelas V SDN Balowerti I Kediri yang berjumlah 37 siswa. Data diperoleh melalui observasi selama proses KBM dan tes untuk mengukur hasil belajar siswa.Selama siklus I dan II telah terjadi peningkatan baik keaktifan siswa maupun hasil belajar siswa. Rata - rata hasil belajar siswa setelah pembelajaran awal adalah 66,$47 ; 51 \%$ belum tuntas; $49 \%$ tuntas. Hasil siklus I nilai rata - rata menjadi 76,35; 24\% belum tuntas; $76 \%$ tuntas. Sedangkan hasil siklus II nilai rata - rata meningkat menjadi 82,03; $11 \%$ belum tuntas; dan $89 \%$ tuntas.Jadi dengan pendekatan scientific dalam pembelajaran mendeskripsikan sifat - sifat magnet dapat membantu meningkatkan keaktifan dan hasil belajar siswa serta dapat membantu memperbaiki cara mengajar guru selama melaksanakan KBM di SDN Balowerti I Kediri.
\end{abstract}

Kata Kunci: kemampuan mendeskripsikan, sifat magnet, scientific.

\section{PENDAHULUAN}

Pada pembelajaran yang dilakukan guru, pendekatan, metode, dan media sangat mempengaruhi hasil belajar siswa. Guru harus mampu menciptakan pembelajaran yang menarik dan menyenangkan agar siswa dapat memahami apa yang telah disampaikan guru tanpa merasa "terbebani" sehingga bisa diperoleh hasil belajar siswa yang maksimal.

Pada pembelajaran mendeskripsikan ciri-ciri magnet yang dilakukan hanya dengan metode ceramah dan penugasan saja kurang untuk memperoleh hasil belajar yang maksimal. Terbukti hasil belajar anak yang diperoleh melalui teknik tes pada pembelajaran ini tidak memuaskan. Rata-rata nilai siswa hanya $66 ; 51 \%$ siswa yang nilainya dibawah KKM (KKM 75); 19 siswa dari 37 siswa yang belum tuntas untuk materi mendeskripsikan sifat - sifat magnet. Oleh karena itu guru merumuskan rencana perbaikan pembelajaran dengan menggunakan pendekatan scientific. Dengan pendekatan ini diharapkan siswa tertarik pada pembelajaran, siswa aktif menemukan konsepnya sendiri dan pada akhirnya hasil belajar siswa meningkat.

Dari hasil pengamatan dan evaluasi guru pada pembelajaran mendeskripsikan ciri-ciri magnet, dapat diketahui bahwa selama pembelajaran siswa pasif, hanya 
menjadi pendengar, pengalaman berikutnya yang didapat siswa dalam pembelajaran adalah mengerjakan tugas-tugas dari guru setelah guru selesai memberi penjelasan. Pengalaman belajar seperti ini mengahasilkan nilai rata-rata evaluasi pembelajaran yang rendah, karena guru hanya mentransfer pengetahuan saja. Siswa hanya diberi tahu, tanpa mencari tahu dulu.

Berdasarkan kondisi diatas permasalahan yang dapat diidentifikasi adalah:

1. Pembelajaran belum menggunakan pendekatan yang sesuai.

2. Siswa belum terlibat aktif dalam pembelajaran.

3. Hasil belajar siswa masih banyak yang dibawah KKM dalam pembelajaran I P

A yang diukur dengan tes pada akhir pembelajaran.

Penelitan ini bertujuan meningkatkan prestasi hasil belajar siswa dalam pembelajaran mendeskripsikan sifat-sifat magnet di Kelas V SDN Balowerti I Kediri.

\section{KAJIAN PUSTAKA}

Sifat Magnet

1. Magnet hanya dapat menarik bendabenda tertentu dalam jangkauannya, artinya tidak semua benda dapat ditarik. Contoh logam yang dapat ditarik oleh magnet yaitu besi, baja, kobalt, dan nikel.

2. Gaya Magnet dapat menembus benda, semakin kuat gaya magnet maka semakin tebal pula benda yang dapat ditembus oleh gaya tersebut. Benda yang bening dan tipis dapat ditembus oleh gaya tarik magnet, misalnya plastik, kertas, kaca, dan kain.

3. Magnet mempunyai dua kutub, yaitu Kutub Utara dan Kutub Selatan.
4. Apabila Kutub yang sejenis / senama didekatkan satu sama lain maka mereka akan tolak menolak, namun apabila kutub yang berbeda didekatkan satu sama lain maka mereka akan tarik menarik

5. Medan magnet akan membentuk gaya magnet. Semakin dekat benda dengan magnet, medan magnetnya semakin rapat, sehingga gaya magnetnya akan semakin besar. Demikian pula sebaliknya.

6. Sifat Kemagnetan dapat hilang atau melemah karena bebarapa penyebab, contohnya apabila terus menerus jatuh, terbakar, dan sebagainya.

\section{Benda Berdasarkan Sifat Kemagnetannya}

Berdasarkan kemagnetannya benda dapat digolongkan menjadi 2, yaitu :

1) Benda Magnetik (Feromagnetik) Feromagnetik adalah benda yang dapat ditarik dengan kuat oleh magnet. Contoh benda ini adalah besi, baja, nikel, dan lain-lain.

2) Benda Non Magnetik

Benda ini terbagi lagi menjadi dua kelompok, yaitu :

a) Paramagnetik, yaitu benda yang dapat ditarik dengan lemah oleh magnet, contohnya alumunium, tembaga, kromium, dan lain-lain.

b) Diamagnetik, yaitu benda menolak magnet, artinya benda ini tidak dapat ditarik oleh magnet, contohnya emas, seng, merkuri, kayu, dan lain-lain.

\section{Pendekatan Scientific}

Pembelajaran dengan pendekatan saintifik adalah proses pembelajaran yang dirancang sedemikian rupa agar peserta didik secara aktif mengonstruk konsep, hukum atau prinsip melalui tahapan- 


\begin{abstract}
tahapan mengamati (untuk mengidentifikasi atau menemukan masalah), merumuskan masalah, mengajukan atau merumuskan hipotesis, mengumpulkan data dengan berbagai teknik, menganalisis data, menarik kesimpulan dan mengomunikasikan konsep, hukum atau prinsip yang "ditemukan". Pendekatan saintifik dimaksudkan untuk memberikan pemahaman kepada peserta didik dalam mengenal, memahami berbagai materi menggunakan pendekatan ilmiah, bahwa informasi bisa berasal dari mana saja, kapan saja, tidak bergantung pada informasi searah dari guru. Oleh karena itu kondisi pembelajaran yang diharapkan tercipta diarahkan untuk mendorong peserta didik dalam mencari tahu dari berbagai sumber melalui observasi, dan bukan hanya diberi tahu.
\end{abstract}

Penerapan pendekatan saintifik dalam pembelajaran melibatkan keterampilan proses seperti mengamati, mengklasifikasi, mengukur, meramalkan, menjelaskan, dan menyimpulkan. Dalam melaksanakan proses-proses tersebut, bantuan guru diperlukan. Akan tetapi bantuan guru tersebut harus semakin berkurang dengan semakin bertambah dewasanya siswa atau semakin tingginya kelas siswa.

Pembelajaran dengan metode scientifik memiliki karakteristik sebagai berikut:

1) berpusat pada siswa.

2) melibatkan keterampilan proses sains dalam mengonstruksi konsep, hukum atau prinsip.

3) melibatkan proses-proses kognitif yang potensial dalam merangsang perkembangan intelek, khususnya keterampilan berpikir tingkat tinggi siswa.

\section{METODE PENELITIAN Subjek dan Tempat Penelitian}

Sebagai subjek penelitian ini adalah siswa Kelas V tahun pelajaran 2015/2016 dengan jumlah siswa 37 anak, terdiri dari 13 siswa laki-laki dan 24 siswa perempuan. Penelitian ini dilakukan di SDN Balowerti I, Kecamatan Kota, Kota Kediri, pada pembelajaran Tema 7 Sub $\quad$ Tema 1 pembelajaran 1.

Teknik Pengumpulan Data

a. Tes : digunakan untuk mendapatkan data tentang hasil belajar siswa.

b. Observasi : digunakan untuk mengumpulkan data tentang partisipasi siswa dan guru dalam pembelajaran mendeskripsikan sifat - sifat magnet dengan menggunakan pendekatan scientific.

c. Diskusi guru dengan teman sejawat untuk merefleksi hasil perbaikan pembelajaran.

\section{Analisa data}

1. Hasil Belajar : dengan menganalisis rata-rata nilai pada evaluasi akhir. Kemudian mengkategorikannya dalam klasifikasi kurang, cukup, baik, dan sangat baik.

2. Aktifitas atau keterlibatan siswa dalam pembelajaran perbaikan : dengan menganalisis tingkat keterlibatan siswa dalam proses pembelajaran perbaikan. Kemudian mengkategorikannya dalam klasifikasi kurang, cukup, baik, dan sangat baik.

3. Penerapan rencana perbaikan pembelajaran mendeskripsikan sifat sifat magnet dengan menggunakan pendekatan scientific : dengan menganalisis tingkat keberhasilan 
perbaikan pembelajaran. Kemudian mengkategorikannya dalam klasifikasi kurang, cukup, baik, dan sangat baik.

\section{HASIL DAN PEMBAHASAN}

Refleksi Awal

Setelah pembelajaran tentang mendeskripsikan sifat - sifat magnet, diperoleh hasil belajar siswa yang kurang memuaskan. Hal tersebut terjadi karena setelah diadakan diskusi dengan teman sejawat ternyata ditemukan berbagai kekurangan yang terjadi selama pembelajaran berlangsung, seperti :

a) Penjelasan guru terlalu abstrak;

b) Guru yang mendominasi kegiatan pembelajaran sehingga siswa menjadi pasif;

c) Kurangnya pemanfaatan media dalam pembelajaran;

d) Metode kurang menarik sehingga terkesan monoton.

Atas dasar analisa data tersebut, maka diadakan perbaikan yaitu :

a) Penjelasan yang terlalu abstrak diubah menjadi yang lebih konkret, yaitu dengan benda aslinya

b) Siswa dilibatkan secara aktif dalam kegiatan pembelajaran

c) Menggunakan berbagai media pembelajaran

d) Menggunakan berbagai metode pembelajaran

\section{Siklus I}

\section{Perencanaan}

a. Membuat rencana perbaikan pembelajaran berdasarkan refleksi awal pada pembelajaran mendeskripsikan sifat - sifat magnet yang sebelumnya kurang berhasil.

b. Menentukan media yang akan digunakan pada perbaikan pembelajaran. c. Menentukan metode yang digunakan dalam pembelajaran.

(Ceramah, tanya jawab, penugasan, dan demonstrasi)

d. Membuat Lembar Kegiatan Siswa.

e. Membuat instrumen yang akan digunakan dalam siklus perbaikan pembelajaran.

f. Menyusun soal evaluasi perbaikan pembelajaran.

Pelaksanaan

a. Membagi kelas menjadi 4 kelompok.

b. Memberikan penjelasan tentang kegiatan yang akan dilakukan.

c. Membagi Lembar Kegiatan Siswa ( LKS ).

d. Memberi pengarahan dalam melakukan kegiatan pada LKS.

e. Mengkomunikasikan hasil kerja kelompok.

f. Membahas hasil kerja kelompok.

g. Membuat pertanyaan untuk kelompok lain.

h. Memberikan kesempatan kepada siswa untuk memberikan tanggapan atas jawaban temannya.

i. Penguatan dan simpulan bersama.

Pada awal siklus pertama pelaksanaan perbaikan pembelajaran sudah sesuai dengan rencana. Tetapi kemudian ditemui beberapa kendala antara lain:

a. Siswa belum terlibat secara aktif bekerjasama dalam kelompok.

b. Siswa menjadi kurang aktif saat kegiatan demonstrasi.

c. Semua siswa ingin menjawab pada saat diadakan tanya jawab untuk soal yang mudah, tetapi tidak ada yang mau menjawab untuk soal yang tingkat kesulitannya cukup tinggi (pertanyaan menalar). 
Pada akhir siklus pertama dari hasil pegamatan guru dan kolaborasi dengan teman sejawat dapat disimpulkan :

a. Siswa mulai terbiasa dengan kondisi belajar kelompok.

b. Yang dipelajari siswa tidak lagi bersifat abstrak tetapi sudah konkret.

\section{Refleksi}

Dari hasil siklus I, sudah ada peningkatan tetapi masih sangat kecil dan belum sesuai dengan target keberhasilan pembelajaran yang direncanakan oleh guru. Oleh karena itu guru merencanakan perbaikan pembelajaran mendeskripsikan sifat - sifat magnet dengan menggunakan pendekatan scientific pada siklus II.

\section{Siklus II}

\section{Perencanaan}

a. Membuat rencana perbaikan pembelajaran siklus II berdasarkan refleksi pada perbaikan pembelajaran siklus I.

b. Menentukan media yang akan digunakan dalam perbaikan pembelajaran siklus II

c. Menentukan metode yang lebih bervariasi lagi dalam perbaikan pembelajaran siklus II

d. Mengurangi kuantitas metode ceramah dengan memberi kesempatan yang lebih banyak kepada siswa untuk melakukan setiap kegiatan pembelajaran.

e. Membuat Lembar Kerja Siswa.

f. Memberi motivasi kepada kelompok untuk lebih aktif dalam pembelajaran.

g. Lebih intensif dalam membimbing siswa yang mengalami kesulitan dalam melakukan eksperimen..

h. Membuat instrumen yang akan digunakan dalam siklus perbaikan pembelajaran.

i. Menyusun alat evaluasi pembelajaran perbaikan. j. Memberikan permainan pada saat pembelajaran.

k. Memberi penguatan dan penghargaan.

\section{Pelaksanaan}

a. Membagi kelas menjadi 7 kelompok.

b. Mengumpulkan informasi dari siswa tentang pemahamannya dari pembelajaran pada siklus 1 .

c. Memberi kesempatan siswa untuk mengajukan pertanyaan kepada guru.

d. Membagi Lembar Kegiatan Siswa ( LKS ).

e. Memberi pengarahan dalam melakukan kegiatan sesuai LKS.

f. Melakukan kegiatan eksperimen.

g. Penyampaian hasil pekerjaan kelompok.

h. Memberikan kesempatan kepada kelompok lain untuk memberikan tanggapan atas hasil pekerjaan kelompok tersebut.

i. Membahas hasil kerja kelompok.

j. Memberikan permainan berupa tepuk benda magnetis dan non magnetis.

k. Penguatan dan simpulan bersama.

l. Merayakan akhir pembelajaran dengan menyanyikan sebuah lagu.

\section{Refleksi}

a. Pelaksanaan pembelajaran berjalan sesuai rencana perbaikan pembelajaran yang dibuat guru. Tugas yang diberikan guru kepada kelompok mampu diselesaikan dengan baik dan tepat waktu. Siswa dalam satu kelompok telah menunjukkan sikap saling bekerja sama untuk dalam melakukan eksperimen.

b. Terjadi peningkatan hasil belajar siswa pada pembelajaran mendeskripsikan sifat-sifat magnet karena guru memberikan pengalaman langsung kepada siswa. 


\section{Perbedaan Siklus I dan Siklus II}

Dalam prosesnya ada beberapa perbedaan pada siklus I dan siklus II.

a) Pada siklus I ada 4 kelompok, tiap kelompok ada 9 siswa.

Pada siklus II ada 7 kelompok, tiap kelompok ada 5 siswa.

Jumlah anggota kelompok diperkecil agar siswa menjadi lebih aktif.

b) Pada siklus II menggunakan media yang lebih banyak.

c) Pada siklus I metode yang digunakan ceramah, tanya jawab, dan demonstrasi. Sedangkan pada siklus II metode yang digunakan ceramah, tanya jawab, penugasan, diskusi kelompok, dan eksperimen.

d) Pada siklus I menggunakan metode demonstrasi (kegiatan diperagakan guru). Sedangkan pada siklus II menggunakan metode eksperimen (tiap kelompok melakukan percobaan sendiri ).

e) Pada siklus II guru memberikan permainan, sehingga siswa merasa senang.

Perbedaan Hasil Siklus I dan Siklus II

\begin{tabular}{|l|l|l|}
\hline Keaktifan Siswa & Siklus I & Siklus II \\
\hline Sangat baik & 4 siswa / & 11 siswa / 30 \\
& $11 \%$ & $\%$ \\
\hline Baik & 4 siswa / & 12 siswa / 32 \\
& $11 \%$ & $\%$ \\
\hline Cukup & 10 siswa / 27 & 10 siswa / 27 \\
& $\%$ & $\%$ \\
\hline Kurang & 19 siswa / 51 & 4 siswa / 11 \\
& $\%$ & $\%$ \\
\hline
\end{tabular}

\begin{tabular}{|l|l|l|}
\hline Hasil Belajar & Siklus I & Siklus II \\
\hline Belum tuntas & 9 siswa / 24 & 4 siswa / 11 \\
& $\%$ & $\%$ \\
\hline Tuntas & 28 siswa / 76 & $\begin{array}{l}33 \text { siswa / 89 } \\
\%\end{array}$ \\
\hline
\end{tabular}

REKAPITULASI HASIL BELAJAR SISWA KELAS V

\begin{tabular}{|c|c|c|c|c|}
\hline No & Nama Siswa & $\begin{array}{l}\text { Nilai } \\
\text { Awal }\end{array}$ & \begin{tabular}{|c|} 
Nilai \\
pada \\
siklus \\
I
\end{tabular} & $\begin{array}{c}\text { Nilai } \\
\text { pada } \\
\text { siklus } \\
\text { II }\end{array}$ \\
\hline 1 & Bagus Puji Satrio & 30 & 50 & 60 \\
\hline 2 & $\begin{array}{l}\text { Adzha Novadila } \\
\text { Rahima }\end{array}$ & 20 & 5 & 60 \\
\hline 3 & Afdhollul Zacky & 50 & 70 & 75 \\
\hline 4 & Agista Noor Azizah & 80 & 90 & 100 \\
\hline 5 & Alfarrell Satriawan & 75 & 85 & 90 \\
\hline 6 & $\begin{array}{l}\text { Alfina Rendra } \\
\text { Fonseca }\end{array}$ & 50 & 70 & 75 \\
\hline 7 & Anindya Larisa Putri & 70 & 80 & 80 \\
\hline 8 & Anita Tri Wulandari & 60 & 75 & 75 \\
\hline 9 & Aulia Yunia Wati & 80 & 90 & 100 \\
\hline 10 & $\begin{array}{l}\text { Ceviano } \\
\text { Chuswidyaramzi }\end{array}$ & 50 & 70 & 75 \\
\hline 11 & Dara Ayu Valen & 70 & 80 & 80 \\
\hline 12 & Dwi Mustika Putri & 60 & 75 & 75 \\
\hline 13 & $\begin{array}{l}\text { Farhan Rizal } \\
\text { Purwono }\end{array}$ & 70 & 80 & 80 \\
\hline 14 & Febrita Valensia & 75 & 80 & 80 \\
\hline 15 & $\begin{array}{l}\text { Halfian Alaudin } \\
\text { Rafsanjani }\end{array}$ & 75 & 85 & 90 \\
\hline 16 & $\begin{array}{l}\text { Jhofanni Alexander } \\
\text { Nillson }\end{array}$ & 70 & 80 & 80 \\
\hline 17 & $\begin{array}{l}\text { Jovanca Naisyla } \\
\text { Windy }\end{array}$ & 40 & 70 & 90 \\
\hline 18 & Laila Amalia Putri & 80 & 90 & 90 \\
\hline 19 & M. Farel A1 Syifa & 70 & 80 & 80 \\
\hline 20 & M. Davit Prasetyo & 80 & 90 & 100 \\
\hline 21 & M. Amar Ma'ruf & 80 & 90 & 100 \\
\hline 22 & $\begin{array}{l}\text { M. Daiva Nur } \\
\text { Adiseno }\end{array}$ & 75 & 80 & 90 \\
\hline 23 & $\begin{array}{l}\text { Najwa Berliana } \\
\text { Dwiarum }\end{array}$ & 50 & 50 & 60 \\
\hline 24 & $\begin{array}{l}\text { Nauzwa Aurura } \\
\text { Angelica }\end{array}$ & 75 & 75 & 80 \\
\hline 25 & $\begin{array}{l}\text { Nayla Fadia } \\
\text { Novariskaputri }\end{array}$ & 50 & 60 & 75 \\
\hline 26 & $\begin{array}{l}\text { Raditya Zakarya } \\
\text { Priyatama }\end{array}$ & 75 & 75 & 80 \\
\hline 27 & Rafifah Hana Nisrina & 75 & 80 & 80 \\
\hline 28 & $\begin{array}{l}\text { Rayhan Agung } \\
\text { Kurniawan }\end{array}$ & 80 & 90 & 100 \\
\hline 29 & $\begin{array}{l}\text { Risanthatia Isti } \\
\text { Kumairoh }\end{array}$ & 70 & 75 & 80 \\
\hline 30 & Septia Natasya Sahira & 75 & 80 & 90 \\
\hline 31 & Shafania Aulia & 80 & 80 & 90 \\
\hline 32 & Shinta Mia Meilana & 75 & 80 & 80 \\
\hline 33 & Sukma Amellia & 80 & 85 & 100 \\
\hline 34 & Syafa Ardha Qischil & 75 & 75 & 85 \\
\hline 35 & $\begin{array}{l}\text { Tahta Alfina } \\
\text { Zazilatunadia }\end{array}$ & 70 & 80 & 80 \\
\hline 36 & Tania Septa Aurelia & 70 & 75 & 75 \\
\hline 37 & $\begin{array}{l}\text { Vellyne Dwi } \\
\text { Krisnandriani }\end{array}$ & 50 & 60 & 80 \\
\hline & Rata - Rata & 66,47 & 76,35 & 82,03 \\
\hline
\end{tabular}

http://ojs.unpkediri.ac.id 


\begin{tabular}{|c|c|c|c|}
\hline Nilai Tertinggi & 80 & 90 & 100 \\
\hline Nilai Terendah & 20 & 50 & 60 \\
\hline
\end{tabular}

\section{SIMPULAN DAN SARAN}

\section{Simpulan}

Berdasarkan hasil penelitian perbaikan pembelajaran dari siklus I dan siklus II ini dapat diambil simpulan bahwa penggunaan pendekatan scientific dapat meningkatkan hasil belajar siswa dalam pembelajaran mendeskripsikan sifat - sifat magnet.

Saran

Telah terbukti penggunaan pendekatan scientific dapat meningkatkan hasil belajar siswa pada materi mendeskripsikan sifat - sifat magnet, maka penulis menyarankan hal-hal sebagai berikut :

1. Melakukan Penelitian Tindakan Kelas untuk memperbaiki pembelajaran yang belum berhasil.

2. Guru dapat memilih media dan metode yang tepat untuk meningkatkan hasil belajar siswanya.

3. Pada umumnya guru mengalami kesulitan dalam membuat karya tulis ilmiah, termasuk membuat laporan penelitian. Oleh karena itu pihak sekolah khususnya dan Dinas Pendidikan Kota/Kabupaten pada umumnya harus memfasilitasi para guru untuk mengikuti pelatihan - pelatihan tentang penulisan karya ilmiah. Sehingga guru akan semakin terlatih dan terampil dalam membuat KTI.

\section{DAFTAR PUSTAKA}

Arikunto, Suharsimi. 2008. Penelitian Tindakan Kelas. Jakarta : Bumi Aksara.
Irene MJA, dkk.2014. Bupena $5 g$ Tema Sejarah Peradaban Indonesia. Jakarta : Erlangga

Sudadi, Imam. 2016. Desain Pembelajaran. Jakarta : Kemendikbud.

Sunardi, dkk. 2016. Teori Belajar. Jakarta : Kemendikbud.

Suparno, Moh. Yunus, 2007. Ketrampilan Dasar Menulis. Jakarta : Pusat Penerbitan UT.

Wardani, I GAK. 2007. Penelitian Tindakan Kelas. Jakarta : Pusat Penerbitan UT.

Winataputra, S. Udin. 2007. Teori Belajar dan Pembelajaran. Jakarta : Pusat Penerbitan UT. 